\title{
Intermittent bundle-branch block in patients with accessory atrio-His or atrio-AV nodal pathways Variants of the Lown-Ganong-Levine syndrome
}

\author{
Benjamin Befeler, Agustin Castellanos, Juan Aranda, Roberto Gutierrez, and Ralph Lazzara \\ From the Cardiovascular Laboratory, Veterans Administration Hospital, University of Miami School of \\ Medicine, Miami, Florida, U.S.A.
}

Intracardiac electrophysiological studies were performed in two patients with a documented history of repetitive supraventricular tachyarrhythmias. Case 1, with short PR interval and narrow $Q R S$ complexes had a short $A H$ interval and intermittent right bundle-branch block. Thus the short $P R$ wide $Q R S$ syndrome is not always a result of the Wolff-Parkinson-White syndrome but can also be seen in the Lown-Ganong-Levine syndrome coexisting with bundle-branch block. Case 2, with normal $P R$ and $A H$ at the lower limits of normal, showed the dual pathway response to atrial pacing that can occur in patients with Lown-Ganong-Levine syndrome. He also had tachycardia-dependent right bundle-branch block and left posterior hemiblock.

Therefore, neither the short $P R$ interval nor the narrow $Q R S$ complexes characterized these forms of pre-excitation. The constant features were, from the clinical viewpoint, the occurrence of repetitive supraventricular tachyarrhythmias, and electrophysiologically the abnormal response to atrial stimulation.

Specialized conducting system studies have implied that patients with short PR intervals, narrow QRS complexes, and repetitive supraventricular tachyarrhythmias have a form of pre-excitation characterized by the presence of an accessory atrio-'low' AV nodal or atrio-His bundle conduction pathway (Durrer, Schuilenburg, and Wellens, 1970; Castellanos et al., 1971, 1975; Coumel et al., 1972; Bisset et al., 1973; Krishnaswami and Geraci, 1974). However, it is not known with certainty whether these pathways are extranodal (bypass tracts) or intranodal. In two recent histopathological studies of the short PR narrow QRS syndrome, accessory atrio-His pathways were found which were different from those described by James (Anderson et al., 1973; Brechenmacher et al., 1974).

Although attention has been focused on the duration of the PR interval and QRS complex the electrophysiological identification and recognition of these pathways rests on the presence of a short AH interval (or one at the lower limits of normal), and on the abnormal behaviour of this interval during atrial stimulation (Caracta et al., 1973; Castellanos et al., 1975; Denes, Wu, and Rosen, 1974). The Received 2 June 1975. present communication emphasizes the fact that narrow QRS complexes are not essential for the diagnosis of these types of accessory pathway (Narula, 1975).

\section{Subjects and methods}

The two patients reported here were referred to the cardiovascular laboratory for electrophysiological evaluation because of a documented history of repetitive supraventricular tachyarrhythmias. His bundle electrograms were recorded, and atrial pacing at increasing rates and with the extra stimulus method was performed as previously described (Castellanos et al., 1971). The procedure was explained, and consent obtained from the patient.

\section{Definitions}

$P A$ interval: conduction time from the area first depolarized by the sinus node to the low right atrium in the vicinity of the AV node.

StA interval: conduction time from the paced (atrial) site to the low right atrium in the vicinity of thy
AV node.

$A H$ interval: conduction time from low right atriuit (close to the AV node) to His bundle. Because of the nature of the underlying electrophysiological abnormalities in the two patients studied this interval was not 
necessarily an index of 'normal' AV nodal conduction time. An AH interval of $50 \mathrm{~ms}$ or less was classified as short, and one of 50 to $60 \mathrm{~ms}$ was at the lower limit of normal.

$H V$ interval: His Purkinje conduction time.

The term 'accessory pathway' will be used to refer to an abnormal electrophysiological atrio-'low' AV nodal or atrio-His communication regardless of its anatomical location.

\section{Case 1}

\section{Case reports}

This 48-year-old hypertensive man had a 4-year history of repetitive supraventricular tachyarrhythmias for which no extracardiac cause had been found. His bundle electrograms recorded during sinus rhythm showed shortening of the PR and AH intervals $(115 \mathrm{~ms}$ and $40 \mathrm{~ms}$ ), with normal PA and HV intervals (Fig. 1). QRS duration was $90 \mathrm{~ms}$. Early in the study the patient developed transient complete right bundle-branch block without any change in the duration of the AV conduction intervals (Fig. 2). Thus, at this time, the patient had a short $P R$ interval with wide $Q R S$ complexes.

High right atrial stimulation at increasing rates produced an AH increment of only $40 \mathrm{~ms}$ at a cycle length of $300 \mathrm{~ms}(200 / \mathrm{min})$. AH Wenckebach occurred at a stimulation rate of $225 / \mathrm{min}$ from high right atrium and at a rate of $250 / \mathrm{min}$ from coronary sinus (Fig. 3). This

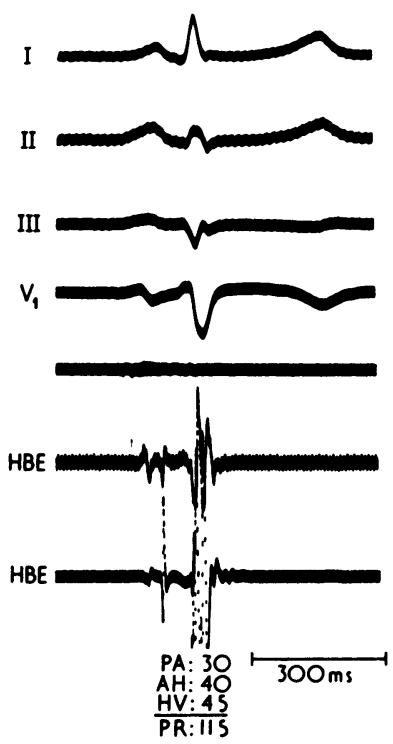

FIG. 1 Case 1. Sinus rhythm with short $P R$ interval, short $A H$ interval, and narrow $Q R S$ complexes. Abbreviations are conventional. $H B E=H i$ s bundle electrographic lead. Whenever the HBE leads are shown the top and bottom ones were obtained with electrodes 11 and $1 \mathrm{~mm}$ apart, respectively. All values are expressed in ms. Paper speed was $100 \mathrm{~mm} / \mathrm{s}$.

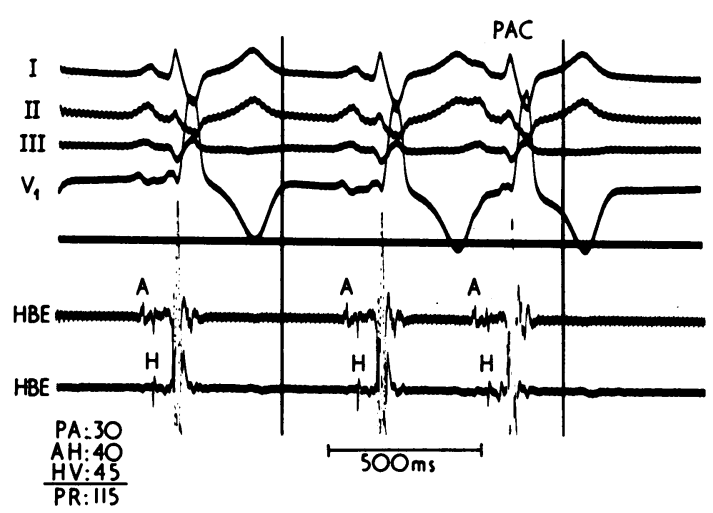

FIG. 2 Case 1. Sinus rhythm with short $P R$ interval, short $A H$ interval, and wide $Q R S$ complexes (right bundle-branch block). HRA=high right atrial bipolar electrographic lead; $P A C=$ spontaneous premature atrial contraction.

response is abnormal (Castellanos et al., 1971; Coumel et al., 1972; Caracta et al., 1973).

Pacing with the extra stimulus technique showed practically no change in the $\mathrm{H}_{1}-\mathrm{H}_{2}$ intervals as the $A_{1}-A_{2}$ intervals were decreased from 700 to $405 \mathrm{~ms}$. At shorter coupling intervals the $\mathrm{H}_{1}-\mathrm{H}_{2}$ interval increased by up to $100 \mathrm{~ms}$ until the effective refractory period of the AH tissues was reached.

Premature stimuli delivered to the coronary sinus at coupling intervals of $225 \mathrm{~ms}$ resulted in a prolonged bout of atrial fibrillation (Fig. 4). The ventricular rates varied between 200 and $250 / \mathrm{min}$. At times the supraventricular impulses were conducted either with a 'complete' left bundle-branch pattern (Fig. 5; first part of Fig. 6) or

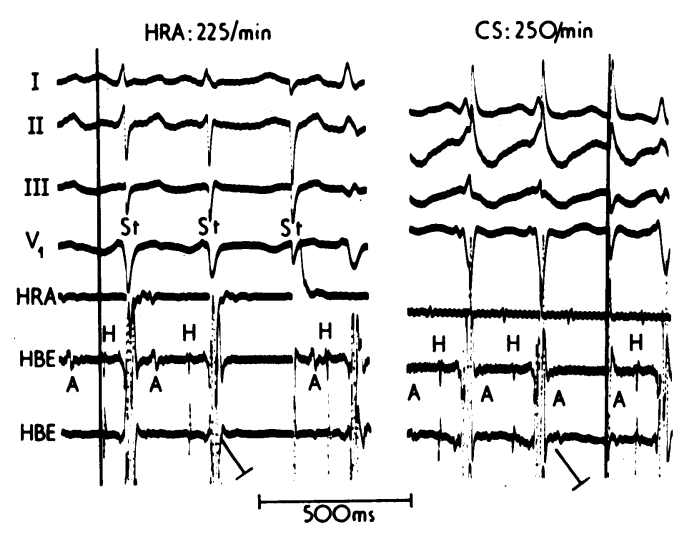

FIG. 3 Case 1. Abnormal response to atrial stimulation at increasing rates. Wenckebach phenomenon occurred at a rate of $225 / \mathrm{min}$ from high right atrium (left) and 250/min from coronary sinus (CS) (right). 


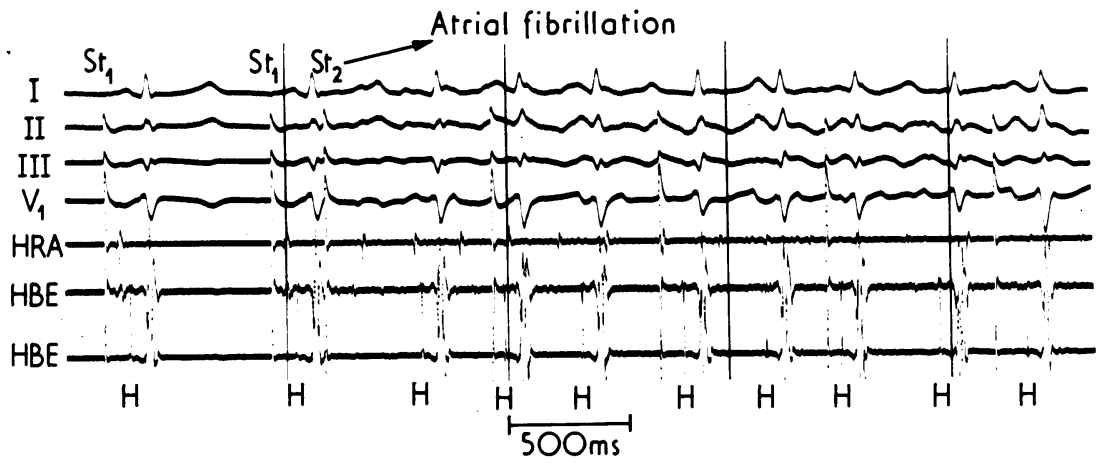

FIG. 4 Case 1. Atrial fibrillation triggered by premature (St2) impulse. St1=driving stimulus. His bundle deflections are best seen in the lower HBE lead, which shows less interference from fibrillatory ('f') waves.

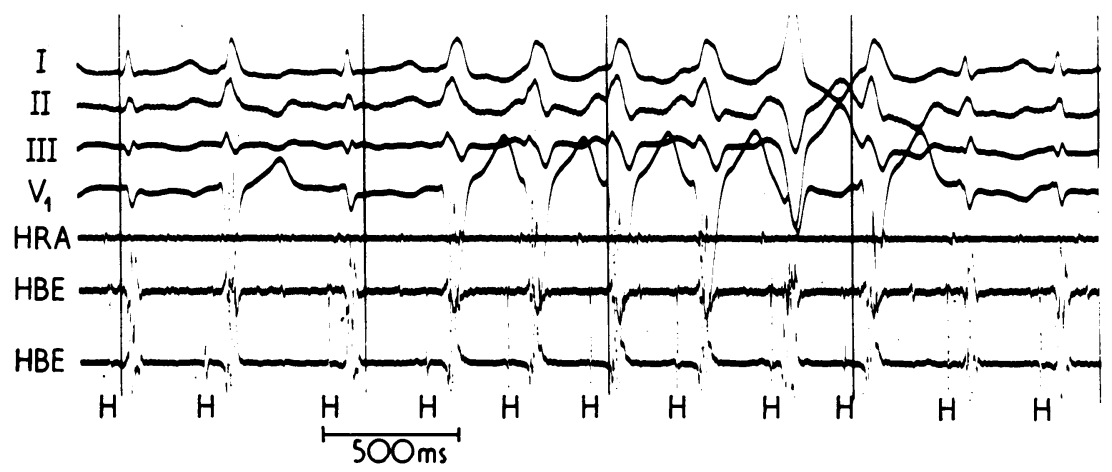

FIG. 5 Case 1. Atrial fibrillation with functional 'complete' left bundle-branch block. His bundle electrograms are best seen in the lower HBE lead, which showed less interference from ' $f$ ' waves.

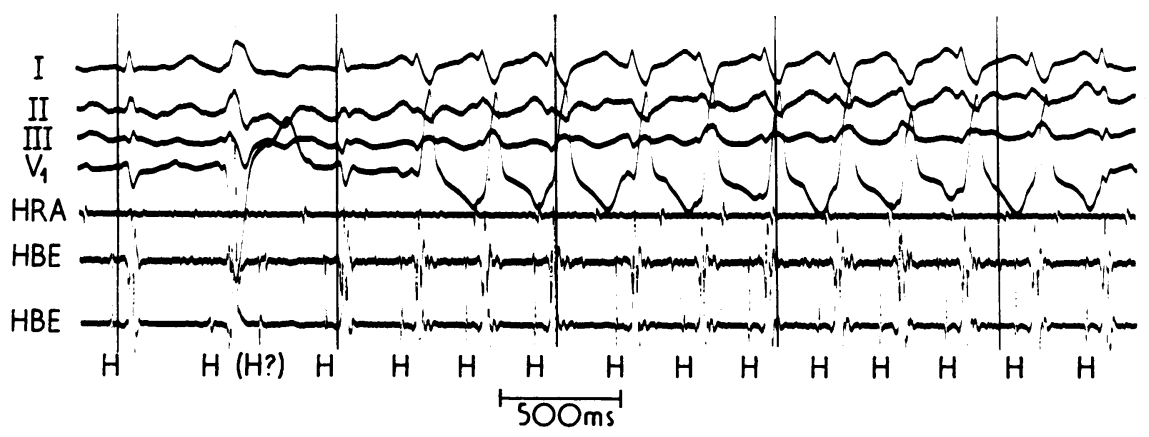

FIG. 6 Case 1. Atrial fibrillation with functional left and right bundle-branch block. His bundle electrograms are best seen in the lower HBE lead which showed less interference from ' $f$ ' waves. The right bundle-branch block morphology is similar to that seen in Fig. 2. 


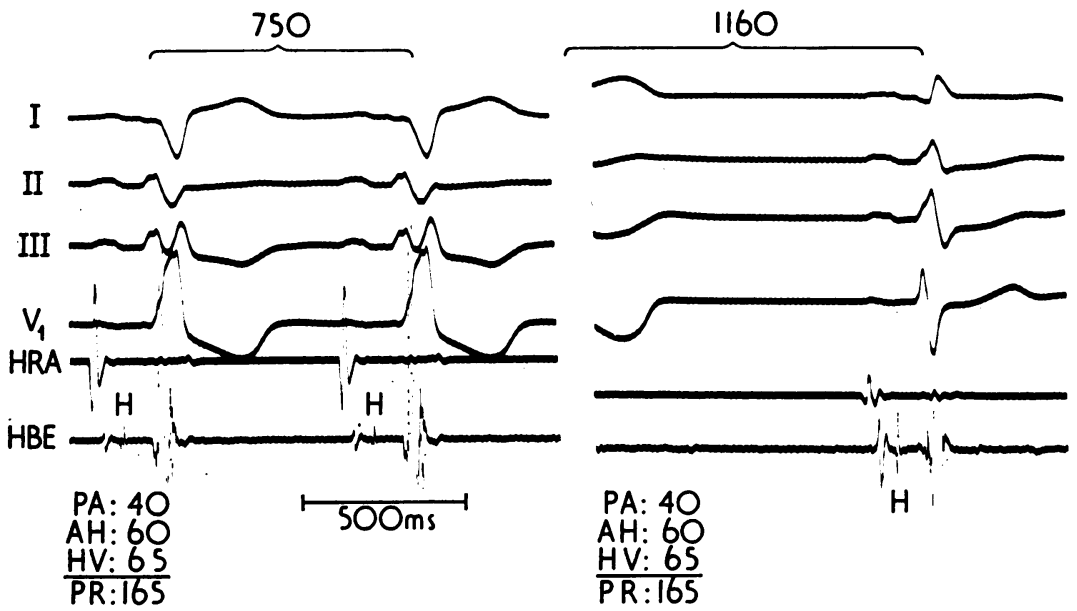

FIG. 7 Case 2. Sinus rhythm and normal PR interval with AH interval at the lower limit of normal. Tachycardia-dependent 'complete' right bundle-branch block and left posterior hemiblock were present when the RR interval was $750 \mathrm{~ms}$ (left). The bifascicular block disappeared when the RR interval increased to $1160 \mathrm{~ms}$ (right). The duration of the AV conduction intervals was the same whether bifascicular block was or was not present.

with a 'complete' right bundle-branch block morphology similar to the one seen in Fig. 2 (last part of Fig. 6).

Clear-cut $\mathbf{H}$ deflections were recorded preceding the corresponding QRS complexes. This was more obvious in the His bundle electrographic lead mounted at the bottom of Fig. 4, 5, and 6, which showed no interference from ' $f$ ' waves.

In conclusion, this patient with short $\mathrm{PR}$ and $\mathrm{AH}$ intervals and repetitive supraventricular tachyarrhythmias had sinus rhythm with intermittent right bundlebranch block and paroxysmal atrial fibrillation with functional bilateral bundle-branch block.

\section{Case 2}

A 52-year-old man with old anterolateral myocardial infarction had a three-year history of palpitations caused by repetitive supraventricular tachyarrhythmias. Right bundle-branch block with left posterior hemiblock occurred at sinus rates greater than $62 / \mathrm{min}$ (Fig. 7, left). However, this bifascicular block disappeared when the cycle length exceeded $960 \mathrm{~ms}$ (Fig. 7, right). The duration of conduction intervals was the same regardless of the presence or absence of wide QRS complexes. At both heart rates the PR interval was normal (165 ms) and the $\mathrm{AH}$ interval was at the lower limits of normal

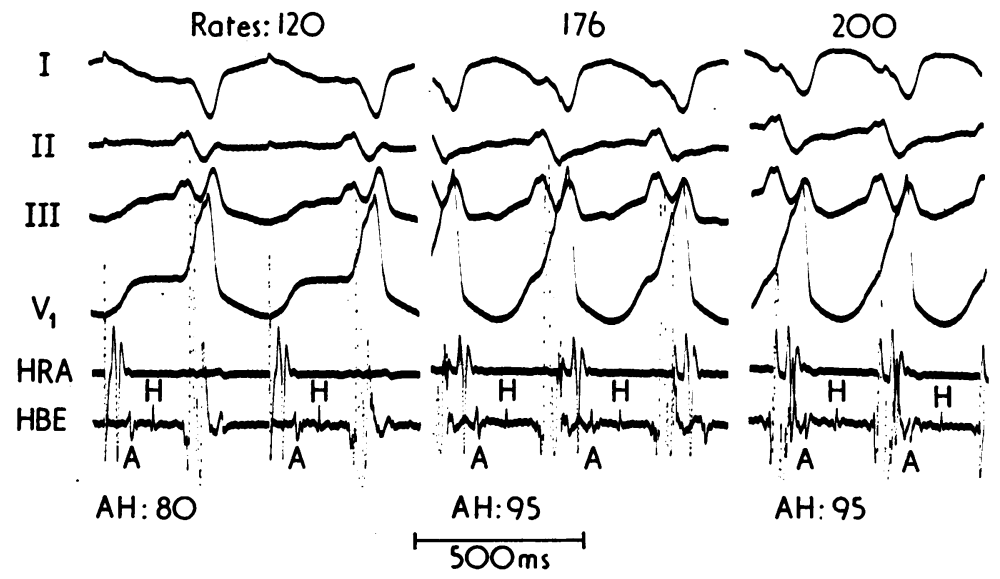

FIG. 8 Case 2. Atrial stimulation at progressively higher rates produced an increase of the $A H$ interval of only $15 \mathrm{~ms}$ from rates of 120/min (left) to 200/min (right). Total AH increment (compared with sinus rhythm, Fig. 7) was $35 \mathrm{~ms}$. 


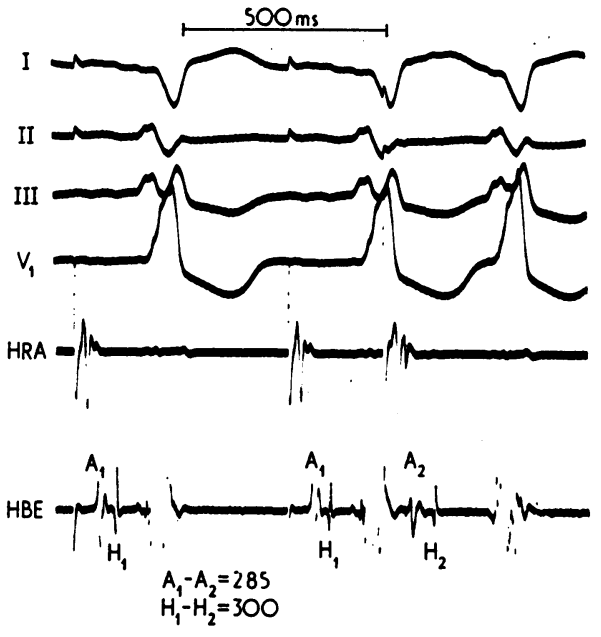

FIG. 9 Case 2. Pacing with the extra stimulus technique showing that at a relatively short $A_{1}-A_{2}$ interval (285 ms) the $\mathrm{H}_{1}-\mathrm{H}_{2}$ interval only measured $300 \mathrm{~ms}$.

$(60 \mathrm{~ms})$. The HV interval was definitely prolonged $(65 \mathrm{~ms})$. The conduction delay most probably occurred in the His bundle (distal to the site from where the $\mathrm{H}$ deflection was recorded) since the HV interval did not shorten when the bifascicular block disappeared.

Mid-right atrial pacing at increasing rates showed that the AH interval increased by only $15 \mathrm{~ms}$ with increasing rate from $120 / \mathrm{min}$ to $200 / \mathrm{min}$ (Fig. 8). The total AH increment (compared with sinus beats in Fig. 7) was only $35 \mathrm{~ms}$, and was therefore less than normal according to Caracta et al. (1973). The cycle length at which HA Wenckebach appeared could not be de- termined since pacing was not performed at rates higher than 200/min.

Pacing with the extra stimulus technique was performed using a driving cycle length of $615 \mathrm{~ms}$. At $A_{1}-A_{2}$ intervals ranging from 600 to $300 \mathrm{~ms}$ the $\mathrm{H}_{1}-\mathrm{H}_{2}$ intervals were almost identical (Fig. 9). This abnormal response indicates that $\mathbf{A}_{\mathbf{2}}$ was not much more delayed than $A_{1}$. However, a sudden increase in $\mathrm{H}_{1}-\mathrm{H}_{2}$ to $410 \mathrm{~ms}$ occurred when $A_{1}-A_{2}$ was decreased to 280 ms (Fig. 10). Apparently the effective refractory period of the accessory pathway was reached, the impulse now being conducted through the AV node (dual pathway response) (Denes et al., 1974). Short runs of atrial flutter were seen at this $A_{1}-A_{2}$ interval (Fig. 10). As in Fig. 7, the right bundle-branch block and the left posterior hemiblock disappeared at an $R R$ interval greater than $960 \mathrm{~ms}$ (last QRS complex).

In summary, this patient with normal PR interval and intermittent bifascicular block had repetitive supraventricular tachyarrhythmias. Though the AH interval was only at the lower limits of normal the response to pacing was abnormal.

\section{Discussion}

Case 1 is an example of the syndrome described by Clerc, Levy, and Cristesco (1938) and Lown, Ganong, and Levine (1952), having a short PR interval, narrow $Q R S$ complexes, and repetitive supraventricular tachyarrhythmias. The results of the specialized intracardiac studies were similar to those reported by other authors, who found that the $\mathrm{AH}$ interval was short and that atrial pacing at increasing rates failed to produce the expected degree of AH prolongation, or that dual pathways were present (Caracta et al., 1973; Denes et al., 1974; Durrer et al., 1970; Castellanos et al., 1971,

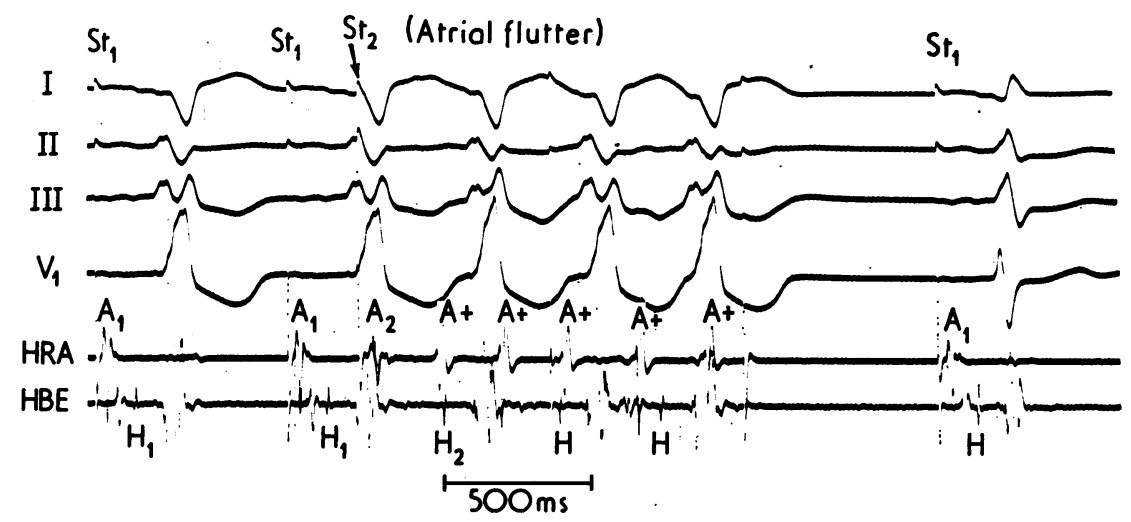

FIG. 10 Case 2. Short run of atrial flutter (with an atrial rate of around 300/min) produced by a premature stimulus $\left(\mathrm{St}_{2}\right)$. Note that the $\mathrm{H}_{1}-\mathrm{H}_{2}$ interval was significantly longer than the $A_{1}-A_{2}$ interval. The bifascicular block disappeared after the end of the arrhythmia because of the corresponding increase in the $R R$ interval. 
1975; Coumel et al., 1972; Bisset et al., 1973; Krishnaswami and Geraci, 1974). On the other hand in the cases of Mandel, Danzig, and Hayakawa (1971), it was the HV interval, not the $\mathrm{AH}$, which was shorter.

In general the majority of authors accept that the short PR narrow QRS complex syndrome can be explained by the presence of an accessory pathway short-circuiting all or most of the area where the 'normal' AV nodal delay occurs. Yet, it has not been determined whether (in patients in whom specialized electrophysiological studies have been performed) the accessory pathways were extra- or intra-AV nodal. However, in a case with short PR, narrow $Q R S$, and atrial flutter with $1: 1 \mathrm{AV}$ conduction, histopathological studies revealed the presence of an atrio-His bypass different from those described by James (Brechenmacher et al., 1974).

Case 1 had intermittent right bundle-branch block during sinus rhythm (Fig. 2). Since the AV conduction intervals did not change, the resultant surface electrocardiographic pattern was that generally attributed to Wolff-Parkinson-White syndrome, namely short PR interval and wide QRS complexes. Moreover, functional bilateral bundlebranch block also occurred during bouts of atrial fibrillation (Fig. 5 and 6). Therefore, this case did not always fulfil the criteria for the Lown-GanongLevine syndrome since one of its features (narrow QRS complexes) was not constantly present (Bisset et al., 1973; Narula, 1975).

These patients are electrophysiologically different from those having ventricular pre-excitation caused by an extra-AV nodal, extra-His bundle bypass (Wolff-Parkinson-White syndrome). The surface electrocardiogram can be misleading when the QRS complexes are wide and the PR interval short, since this pattern can be the result of either the WolffParkinson-White syndrome (in which exclusive Kent bundle conduction occurs) (Castillo et al., 1973) or the Lown-Ganong-Levine syndrome with bundle-branch block (Fig. 2). On the other hand, some patients with the Wolff-Parkinson-White syndrome can have normal PR intervals and wide QRS complexes during atrial pacing (Durrer and Wellens, 1974) or when the pre-excitation is intermittent and the impulses are conducted through the normal pathway with bundle-branch block (Castillo et al., 1973).

Some of the reported patients with short PR intervals and repetitive supraventricular tachyarrhythmias did not have a definitely short AH interval (Caracta et al., 1973; Narula, 1975). For instance, the $\mathrm{AH}$ interval measured $70 \mathrm{~ms}$ in 8 of the 18 subjects studied by Caracta et al. (1973), though in these patients the AH interval did not show the 'normal' increase during atrial pacing at progressively higher rates.

In other cases with repetitive supraventricular tachyarrhythmias and an abnormal response to atrial stimulation (as defined previously) the PR was not short. Three of the patients studied by Caracta et al. (1973) had AH and HV intervals of $80 \mathrm{~ms}$ and $40 \mathrm{~ms}$, respectively. Addition of the PA interval to those values would result in a PR interval greater than $120 \mathrm{~ms}$. Four of the 15 cases studied by Coumel et al. (1972), had PR intervals exceeding $120 \mathrm{~ms}$. Case 2 (Fig. 7 to 10 ) can be included in this category, but also had tachycardiadependent 'complete' right bundle-branch block and left posterior hemiblock. Hence, neither the short PR interval nor the narrow QRS complexes characteristic of the Lown-Ganong-Levine syndrome were present in this patient.

The features that Cases 1 and 2 had in common were the history of repetitive supraventricular tachyarrhythmias, and the abnormal response to atrial stimulation.

\section{Addendum}

In a recent pathological study (British Heart fournal (1975), 37, 853), Brechenmacher noted an atrio-His bundle tract different from those described by James in a patient with bilateral bundle-branch block.

\section{References}

Anderson, R. H., Thapar, M. K., Arnold, R., and Jones, R. G. (1973). Study of conducting tissue in a case of ventricular pre-excitation. British Heart fournal, 35, 566.

Bisset, J. K., Thompson, A. J., deSoyza, N., and Murphy, M. L. (1973). Atrioventricular conduction in patients with short PR interval and normal QRS complexes. British Heart Fournal, 35, 123.

Brechenmacher, L., Laham, J., Iris, L., Gerbaux, A., and Lenègre, J. (1974). Etude histologique des voies anormales de conduction dans un syndrome de Wolff-ParkinsonWhite et dans un syndrome de Lown-Ganong-Levine. Archives des Maladies du Coeur et des Vaisseaux, 67, 507.

Castellanos, A., Jr., Castillo, C. A., Agha, A. S., and Tessler, M. (1971). His bundle recordings in patients with short P-R intervals, narrow QRS complexes and paroxysmal tachycardias. Circulation, 43, 667.

Castellanos, A., Vagureiro, M. C., Befeler, B., and Myerburg, R. J. (1975). Syndrome of short P-R, narrow QRS and repetitive supraventricular tachyarrhythmias: the possible occurrence of the R-on-T phenomenon and the limits of the syndrome. European fournal of Cardiology, 2, 337.

Castillo, C. A., Castellanos, A., Jr., Befeler, B., Myerburg, R. J., Agha, A. S., and Vagueiro, M. C. (1973). Arrival of excitation at right ventricular apical endocardium in Wolff-Parkinson-White syndrome type $A$, with and without right bundle-branch block. British Heart fournal, 35, 594.

Caracta, A. N., Damato, A. N., Gallagher, J. J., Josephson, M. C., Varghese, P. J., Lau, S. H., and Westura, E. E. (1973). Electrophysiologic studies in the syndrome of short P-R interval, normal QRS complex. American fournal of Cardiology, 31, 245. 
Clerc, A., Levy, R., and Cristesco, C. (1938). A propos du raccourcissement permanent de l'espace $P-R$ de l'electrocardiogramme sans déformation du complexe ventriculaire. Archives des Maladies du Coeur et des Vaisseaux, 31, 569.

Coumel, P., Waynberger, M., Slama, R., and Bouvrain, Y. (1972). Le syndrome du P-R court, avec complexe QRS normal. Particularités électrocardiographiques. Archives des Maladies du Coeur et des Vaisseaux, 65, 161.

Denes, P., Wu, D., and Rosen, K. M. (1974). Demonstration of dual $\mathrm{A}-\mathrm{V}$ pathways in a patient with Lown-GanongLevine syndrome. Chest, 65, 343.

Durrer, D., Schuilenburg, R. N., and Wellens, H. J. J. (1970). Pre-excitation revisited. American fournal of Cardiology, 25, 690.

Durrer, D., and Wellens, H. J. J. (1974). The WolffParkinson-White syndrome anno 1973. European fournal of Cardiology, 1, 347.

Krishnaswami, V., and Geraci, A. R. (1974). Accelerated A-V conduction associated with complete A-V block. American Heart Fournal, 88, 463.
Lown, B., Ganong, W. F., and Levine, S. A. (1952). The syndrome of short $\mathrm{P}-\mathrm{R}$ interval, normal $\mathrm{QRS}$ complex and paroxysmal rapid heart action. Circulation, 5, 693.

Mandel, W., Danzig, R., and Hayakawa, H. (1971). LownGanong-Levine syndrome: a study using His bundle electrograms. Circulation, 44, 696.

Narula, O. S. (1975). Electrophysiological evaluation of accessory conduction pathways. In His Electrocardiography and Clinical Electrophysiology, p. 321. Ed. by O. S. Narula. F. A. Davis, Philadelphia.

Requests for reprints to Professor Agustin Castellanos, University of Miami School of Medicine, Division of Cardiology, P.O. Box 520875, Miami, 33152, Florida, U.S.A. 